\title{
Quantitative mapping of surface elastic moduli in silica-reinforced rubbers and rubber blends across the length scales by AFM
}

\author{
Peter Schön · Saurabh Dutta • Morteza Shirazi • \\ Jacques Noordermeer • G. Julius Vancso
}

Received: 18 September 2010/Accepted: 6 January 2011/Published online: 22 January 2011

(C) The Author(s) 2011. This article is published with open access at Springerlink.com

\begin{abstract}
The surface elastic moduli of silica-reinforced rubbers and rubber blends were investigated by atomic force microscopy (AFM)-based HarmoniX material mapping. Styrene-butadiene rubbers (SBR) and ethylene-propylenediene rubbers (EPDM) and SBR/EPDM rubber blends with varying concentrations of silica nanoparticles $(0,5,10,20$, 50 parts per hundred rubber, $\mathrm{phr}$ ) were prepared to investigate the effect of different composition on the resulting morphology, filler distribution and elastic moduli of a specific rubber or rubber blend sample. For SBR, the elastic modulus values varied from $0.5 \mathrm{MPa}$ for unfilled SBR to $5 \mathrm{MPa}$ for $50 \mathrm{phr}$ reinforced SBR with the increase in the concentration of filler. For EPDM, the corresponding values increased from 1.4 MPa for unfilled EPDM to 4.5 MPa for $50 \mathrm{phr}$ reinforced EPDM. Local stiff and soft domains in silica-reinforced SBR and EPDM rubbers and rubber blends were identified by HarmoniX AFM imaging. While the stiff silica particles show modulus values as high as $2 \mathrm{GPa}$, the rubber matrix reveals modulus values in the range of ca. $30 \mathrm{MPa}$ for the rubber blends to ca. $300 \mathrm{MPa}$ for the unfilled rubbers. The lower value of elastic modulus of the EPDM
\end{abstract}

P. Schön · S. Dutta $\cdot$ G. Julius Vancso $(\bowtie)$

Materials Science and Technology of Polymers,

$\mathrm{MESA}^{+}$Institute for Nanotechnology, University of Twente,

7500 AE Enschede, The Netherlands

e-mail: g.j.vancso@utwente.nl

M. Shirazi · J. Noordermeer $(\bowtie)$

Elastomer Technology and Engineering, Engineering

Technology Department, University of Twente,

7500 AE Enschede, The Netherlands

e-mail: j.w.m.noordermeer@utwente.nl

M. Shirazi · J. Noordermeer

Dutch Polymer Institute DPI, 5600 PLX Eindhoven,

The Netherlands phase in the blend, compared to the blank EPDM compound can be attributed to the presence of Sunpar oil in the compound which has a very good affinity with EPDM and decreases the rubber modulus. The elastic moduli maps revealed an increase of the areal fraction of silica particles showing an intrinsic surface modulus value with rising silica content in the compound preparation mixture. HarmoniX AFM measurements revealed the formation of larger silica aggregates in EPDM in contrast to SBR where isolated silica particles were observed. For silica-reinforced rubber blends a phase separation into a soft (ca. $40 \mathrm{MPa}$ ) and a significantly harder phase could be observed (ca. $500 \mathrm{MPa}-1.5 \mathrm{GPa}$ ) indicating the incorporation of silica particles in the SBR phase. Using HarmoniX AFM imaging significantly higher surface elastic moduli were observed compared to those obtained by bulk tensile testing. Possible reasons for the observed differences between bulk modulus values and those measured by AFM are discussed in detail, including the aspect of different averaging procedures like inherent to surface probing by AFM versus bulk tensile testing, different filler distributions in SBR and EPDM and the AFM modulus calibration procedures.

\section{Introduction}

Due to their outstanding mechanical properties rubbers and rubber blends represent a class of highly important materials $[1,2]$. Rubbers are commonly used after reinforcement with fillers such as carbon black and silica particles which fundamentally change the mechanical properties of the rubber [3]. Reinforcing fillers give the rubber unique properties combining high elasticity with high strength. Carbon black has been used since the early 1900s as the preferred reinforcing filler for rubber. It is available in a great variety of 
types and used in virtually all sorts of rubbers. The use of silica for reinforcement emerged in the early 1950s and has experienced the largest breakthrough in the last decade. The replacement of carbon black by easy-dispersion silica fillers in combination with special rubber types under selection of an appropriate coupling agent, allows for a significantly reduced rolling resistance. This leads to a reduced fuel consumption of the vehicle, while the wet traction and abrasion resistance are kept at the same level.

The homogeneity of the filler distribution is of fundamental importance and influences the mechanical properties of reinforced rubbers. Until recently, the dispersion of fillers in rubbers has been determined predominantly by optical and transmission electron microscopy (TEM). Electron microscopy can be used for the characterization of rubber blends and filler distributions, however, it is hampered by limitations regarding the detection and localization of $\mathrm{SiO}_{2}$ nanoparticles. In addition, TEM requires cumbersome preparation of microtomed sections [3].

Atomic force microscopy (AFM) has been widely used to study the structure and morphology of rubbers and polymers with nanoscale resolution [4-6]. It has also been successfully applied to provide insights into surface morphology of composites. Rubber morphologies and carbon black microdispersions have also been studied by AFM [7-10].

The possibility to characterize rubber samples at very high spatial resolution $<10 \mathrm{~nm}$ by means of AFM under ambient conditions promises to localize and identify $\mathrm{SiO}_{2}$ filler particles in rubber blend samples and gain deeper insights into composition-property relationships of rubber and rubber blend samples with special attention to the effect of filler distribution on the mechanical properties. Tapping mode AFM (TMAFM) is commonly used for probing the topography and composition of rubber surfaces [4]. However, quantitative mechanical mapping is not possible with conventional phase imaging as the phase signal is related to the energy dissipation of the tapping tip which cannot be directly translated into the variation of mechanical moduli $[11,12]$. Phase contrast results from dissipation of cantilever energy and shifts of cantilever resonant frequency. In conventional TMAFM, it is difficult to relate the phase differences to the actual quantitative mechanical properties because they depend on a mixture of elastic, adhesive, and dissipative properties of the sample and of the AFM imaging parameters such as set point, drive amplitude or the ratio of the free air amplitude to the drive amplitude.

Traditional AFM force probing techniques like nanoindentation and force volume AFM imaging have been successfully applied to characterize the mechanical properties of polymer surfaces [13-15]. Using appropriate mechanical contact models, local elastic moduli can be derived from the recorded force versus deformation curves. However, these techniques face difficulties with respect to comparatively low scan speeds, large deformation depths leading to damage of the sample and thus limited lateral resolution.

The AFM-based HarmoniX Imaging has been introduced as a mechanical property mapping technique providing high resolution ( $>10 \mathrm{~nm}$ laterally) quantitative mechanical characterization of stiffness, elastic modulus, adhesion, and energy dissipation of a polymer surface [16-19].

In this study, the surface elastic moduli of silica-reinforced rubbers and rubber blends were investigated by AFM-based HarmoniX material mapping and compared to the corresponding macroscopic tensile values.

\section{Experimental section}

\section{Materials}

The elastomers selected for this study were styrenebutadiene rubbers (SBR) and ethylene-propylene-diene rubbers (EPDM) and blends thereof. Solution polymerized SBR containing $37.5 \mathrm{phr}$ oil (Buna ${ }^{\circledR}$ VSL 5025-0 HM) containing $25 \mathrm{wt} \%$ styrene and $75 \mathrm{wt} \%$ butadiene (50 wt $\%$ vinyl and $25 \mathrm{wt} \%$ cis/trans butadiene) was obtained from Lanxess GmbH, Germany; EPDM (Keltan $® 4703$ ) (HENBEPDM) consisting of $9 \mathrm{wt} \%$ ethylidene-norbornene (ENB), $48 \mathrm{wt} \%$ ethylene and a propylene content of $43 \mathrm{wt} \%$ was obtained from DSM Elastomers B.V., the Netherlands. Two different grades of precipitated silica i.e., Ultrasil ${ }^{\circledR} \mathrm{VN} 3$ and Ultrasil 7005, and Si69® (Bis[3-(triethoxysilyl) propyl] tetrasulfide), a bifunctional silane coupling agent, were obtained from Degussa (now Evonik), Germany. Additional compounding ingredients or additives used were extra pure grade zinc oxide (Merck, Germany), reagent grade sulfur powder purified by refining with particle size-100 mesh (Sigma-Aldrich), 95\% pure stearic acid (Sigma-Aldrich), poly(2,2,4-trimethyl-1,2-dihydroquinoline) resin or TMQ (Flexsys B.V., the Netherlands), 2-mercapto benzothiazole or MBT (Merck, Germany), poly(ethylene glycol) 2000 (Fluka), Tetramethyl thiuram disulfide $97 \%$ or TMTD (Merck, Germany) and Sunpar 150, a paraffinic oil used for effective dispersion of silica.

\section{Preparation of rubber compounds}

The SBR and EPDM compounds were prepared with varying amounts of silica filler. Depending on the amount of silica, the amount of silane $(\mathrm{Si} 69 \AA)$ ) and paraffinic oil (Sunpar 150) needed to functionalize and disperse the silica particles was varied. The concentration of all other components like $\mathrm{ZnO}$ (activator), TMQ (antioxidant), stearic acid (co-activator) and curatives was kept the same for each series of SBR and EPDM compounds. An overview of 
the different rubber compounds prepared with the corresponding amounts (phr) of the components is given in Table 1. To see any possible differences in particle/ aggregate/agglomerate sizes, SBR and EPDM samples were prepared with two different types of silica, Ultrasil VN3 (conventional silica) and Ultrasil 7005 (easy-dispersion silica) which differ in their dispersion characteristics. Additional blend samples were made with different ratios of SBR/EPDM with the same amount of silica (20 phr) to study the distribution of silica in the two phases.

Mixing of the components

The SBR, EPDM, and SBR/EPDM blend compounds were prepared by mixing the elastomers and other compounding ingredients in a Brabender ${ }^{\circledR} 350$ S Plasticorder lab station internal mixer with a capacity of $370 \mathrm{~mL}$. For all compounds, the same mixing procedure was followed, as described by Reuvekamp et al. [20-22]. The mixing process consisted of three steps. For a particular compound, all its components were weighed according to the recipe in Table 1 and mixed in the internal mixer following the procedure described in Table 2 . The temperature during the first mixing step was set to $50{ }^{\circ} \mathrm{C}$ with a rotor speed of $80 \mathrm{rpm}$ and a fill factor of $70 \%$ was used. After the first mixing step, the mixed compound was taken out and sheeted out on a Schwabenthan two roll mill to homogenize the compound. Subsequently a second mixing step was carried out in the internal mixer at a temperature of $140{ }^{\circ} \mathrm{C}$ and at the same rotor speed. This step is required to functionalize the silica particles with the silane. The compound was then taken out and passed once more through the two roll mill. A third mixing step was carried out on the same two roll mill where the curatives (S, MBT, and TMTD) were mixed into the rubber compound.

\section{RPA test}

After the curatives were mixed into the sample, the curing properties of the compounds were determined with an RPA 2000 dynamic mechanical rheological tester (Alpha Technologies, USA). The optimal vulcanization time $\left(t_{90}\right)$ and scorch time $\left(t_{\mathrm{S} 2}\right)$ of the compounds were determined. One sample each $(5 \mathrm{~g})$ from the SBR, EPDM, and SBR/ EPDM blend compounds was tested with the RPA and the conditions obtained were applied to the rest of the compounds based on the same elastomer. Based on the $t_{90}$ obtained from the rheograms, the curing conditions for the SBR samples were determined to be $150{ }^{\circ} \mathrm{C}$ for $30 \mathrm{~min}$ while for EPDM it was selected as $180{ }^{\circ} \mathrm{C}$ for $45 \mathrm{~min}$. For the rubber blends $170{ }^{\circ} \mathrm{C}$ for $20 \mathrm{~min}$ were selected. The SBR and EPDM samples were cured inside a Wickert Lab Press WLP 1600 (Wickert Maschinenbau GmbH, Landau, Germany) at a pressure of 100 bar. The cured specimen obtained in the form of $85 \mathrm{~mm} \times 85 \mathrm{~mm}$ square shaped sheet with a thickness of $2 \mathrm{~mm}$ was ready for preparing samples for AFM analysis.

\section{Tensile measurements}

The macroscopic elastic modulus of bulk samples was obtained with a Zwick/Roell Z 1.0 tensile tester. Six measurements were done for each cured compound and the values of the average elastic moduli were recorded.

\section{AFM}

A strip of the cured rubber sample was cut using scissors followed by cutting a small piece from the strip using a sharp razor blade so as to obtain a smooth surface and

Table 1 Different rubber compounds prepared with the amounts of components indicated in phr

\begin{tabular}{|c|c|c|c|c|c|c|c|c|c|}
\hline Samples & Rubber-phr silica & SBR & EPDM & Si 69 & Sunpar 150 & Stearic acid & $\mathrm{ZnO}$ & TMQ & PEG \\
\hline 1. & SBR-0 phr & 137.5 & - & - & - & 2 & 4 & 1.25 & - \\
\hline 2. & SBR-5 phr & 137.5 & - & 0.5 & - & 2 & 4 & 1.25 & - \\
\hline 3. & SBR-10 phr & 137.5 & - & 1 & - & 2 & 4 & 1.25 & - \\
\hline 4. & SBR-20 phr & 137.5 & - & 2 & - & 2 & 4 & 1.25 & - \\
\hline 5. & SBR-50 phr & 137.5 & - & 5 & - & 2 & 4 & 1.25 & - \\
\hline 6. & EPDM-0 phr & - & 100 & - & - & 1 & - & 1.25 & - \\
\hline 7. & EPDM-5 phr & - & 100 & 0.5 & 2 & 1 & - & 1.25 & 2 \\
\hline 8. & EPDM-10 phr & - & 100 & 1 & 4 & 1 & - & 1.25 & 2 \\
\hline 9. & EPDM-20 phr & - & 100 & 2 & 8 & 1 & - & 1.25 & 2 \\
\hline 10. & EPDM-50 phr & - & 100 & 5 & 20 & 1 & - & 1.25 & 2 \\
\hline 11. & 50/50 SBR/EPDM-20 phr & 68.75 & 50 & 2 & 5 & 1.5 & 2 & 1.25 & 1 \\
\hline 12. & 50/50 SBR/EPDM-50 phr & 68.75 & 50 & 5 & 10 & 1.5 & 2 & 1.25 & 1 \\
\hline 13. & 30/70 SBR/EPDM-20 phr & 41.25 & 70 & 2 & 5 & 1.5 & 2 & 1.25 & 1.4 \\
\hline 14. & 70/30 SBR/EPDM-20 phr & 96.25 & 30 & 2 & 5 & 1.5 & 2 & 1.25 & 0.6 \\
\hline
\end{tabular}


Table 2 Mixing procedure for rubber components in the internal mixer

\begin{tabular}{ll}
\hline Time $(\mathrm{min} \mathrm{sec})$ & Action \\
\hline 0.00 & Open ram, add rubber \\
0.20 & Close ram \\
1.20 & Add $1 / 2$ silica, $1 / 2$ silane, $1 / 2 \mathrm{ZnO}$, \\
& $1 / 2$ stearic acid, $1 / 2$ TMQ \\
2.20 & Close ram \\
3.20 & Open ram, add $1 / 2$ silica, $1 / 2$ silane, \\
& $1 / 2$ ZnO, $1 / 2$ stearic acid, $1 / 2$ TMQ \\
4.20 & Close ram \\
7.20 & Open ram, sweep and dump \\
Step 2 & \\
0.00 & Load compound \\
5.00 & Dump \\
\hline
\end{tabular}

avoid any rough edges. The cut sample was glued to a metal disk using a two-component epoxy glue. The glue was allowed to set for $2-3 \mathrm{~h}$. The sample surface was cleaned with nitrogen air before imaging to remove any loose particles sticking to the surface.

The morphology of smooth, cross-sectioned areas at the specimen surface was examined by AFM. For HarmoniX tapping torsional harmonic cantilevers (HarmoniX Probes, HMX, HMX-S, Veeco Instruments) (resonance frequency $\sim 60 \mathrm{kHz}$, spring constant $1-1.8 \mathrm{~N} / \mathrm{m}$ ) were used to generate time-varying tip-sample forces. HarmoniX measurements were done in air under ambient conditions using a Multimode AFM with a NanoScope V controller and NanoScope version 7.30 software (Veeco/Digital Instruments, Santa Barbara, CA). Cantilevers were calibrated using a standard PS/LDPE sample according to the method reported by Sahin et al. [17]. HarmoniX TMAFM was operated utilizing a cantilever vibration free amplitude of $1.5 \mathrm{~V}$ in air. The level of the force applied to the surface was adjusted by the amplitude set point, which was used for the feedback control, to ca. $40 \%$ of the free amplitude. Imaging was performed at $0.5-1 \mathrm{~Hz}$ scan rates.

Image processing and data analysis were performed with the NanoScope software version 7.30 and version 8.0 and NanoScope Analysis version 1.10.

\section{Results and discussion}

Tensile measurements

The bulk elastic moduli for the SBR-silica composites vary from 0.5 MPa for SBR without any silica filler to about $5 \mathrm{MPa}$ for $50 \mathrm{phr}$ silica-reinforced SBR, thus showing a 10 times increase in stiffness (Table 3). In case of EPDM, the observed modulus values range from 1.4 MPa for EPDM
Table 3 Elastic modulus values of SBR and EPDM samples reinforced with silica as obtained by tensile measurements

\begin{tabular}{lcl}
\hline Elastomers & $\begin{array}{l}\text { Silica content } \\
(\mathrm{phr})\end{array}$ & $\begin{array}{l}\text { Average E-modulus } \\
(\mathrm{MPa})\end{array}$ \\
\hline SBR & 0 & 0.5 \\
SBR & 20 & 0.8 \\
SBR & 50 & 4.9 \\
EPDM & 0 & 1.4 \\
EPDM & 10 & 1.9 \\
EPDM & 20 & 2.7 \\
EPDM & 50 & 4.4 \\
SBR/EPDM (50/50 blend) & 20 & 3.5 \\
SBR/EPDM (50/50 blend) & 50 & 5.5 \\
\hline
\end{tabular}

without silica to $4.4 \mathrm{MPa}$ for $50 \mathrm{phr}$ silica-reinforced EPDM. The smaller increase in modulus here is related to a combination of factors like less interaction or poor mixing of the silica with EPDM as compared to SBR.

The observed values of elastic moduli for the 50/50 blends of SBR and EPDM, filled with 20 and 50 phr silica are larger than either value of the corresponding individual SBR or EPDM samples.

Precipitated silica fillers belong to the class of reinforcing fillers and in general, are expected to improve the mechanical properties of elastomers like tensile strength, hardness, elongation at break, etc. [21-24]. Indeed the tensile measurements reveal an increase in the static elastic modulus being observed with raising concentration of the silica filler for both, SBR and EPDM composites.

\section{HarmoniX AFM imaging}

The morphology of smooth, cross-sectioned areas of the rubber specimen surfaces were examined by AFM. HarmoniX AFM imaging was applied to obtain corresponding DMT elastic moduli maps.

Local stiff and soft domains in silica-reinforced SBR and EPDM rubbers and rubber blends can be identified by HarmoniX AFM imaging. The stiffer silica particles can be separately identified from the surrounding soft rubber matrix. While the stiff silica particles show modulus values as high as $2 \mathrm{GPa}$, the rubber matrix reveals modulus values in the range of $30 \mathrm{MPa}$ (in case of rubber blends)-300 $\mathrm{MPa}$ (individual rubbers). The significant discrepancies between tensile modulus values and those measured by AFM are discussed in a separate paragraph below.

\section{SBR-silica}

Height and corresponding modulus maps obtained from silica-reinforced SBR are shown in Fig. 1. Isolated particle 

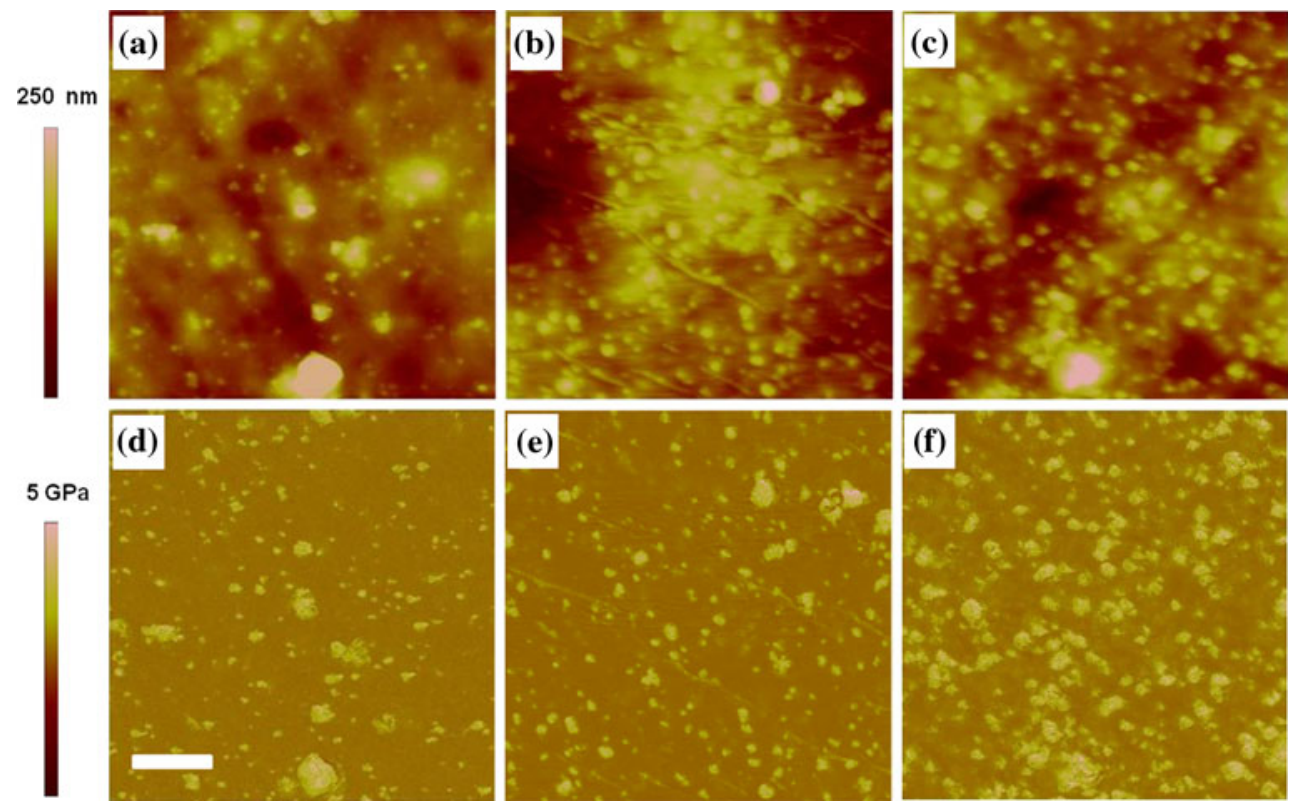

Fig. 1 Height (a, b, c) and corresponding DMT modulus (d, e, f) images as obtained by HarmoniX TMAFM. Samples: SBR filled with Ultrasil 7005; a, d: 5 phr Ultrasil 7005; b, e: 10 phr Ultrasil
7005, and c, f: 20 phr Ultrasil 7005; scan sizes: $5 \times 5 \mu \mathrm{m}$. Scale bar: $1 \mu \mathrm{m}$; $z$-scales: height: $250 \mathrm{~nm}$, DMT modulus: $5 \mathrm{GPa}$
Fig. 2 Phase (left) and DMT Modulus (right) images of SBR5 phr Ultrasil 7005; scan sizes: $5 \times 5 \mu \mathrm{m}$. Scale bar: $1 \mu \mathrm{m}$; z-scales: phase: $30^{\circ}, \mathrm{DMT}$ modulus: $2.5 \mathrm{GPa}$
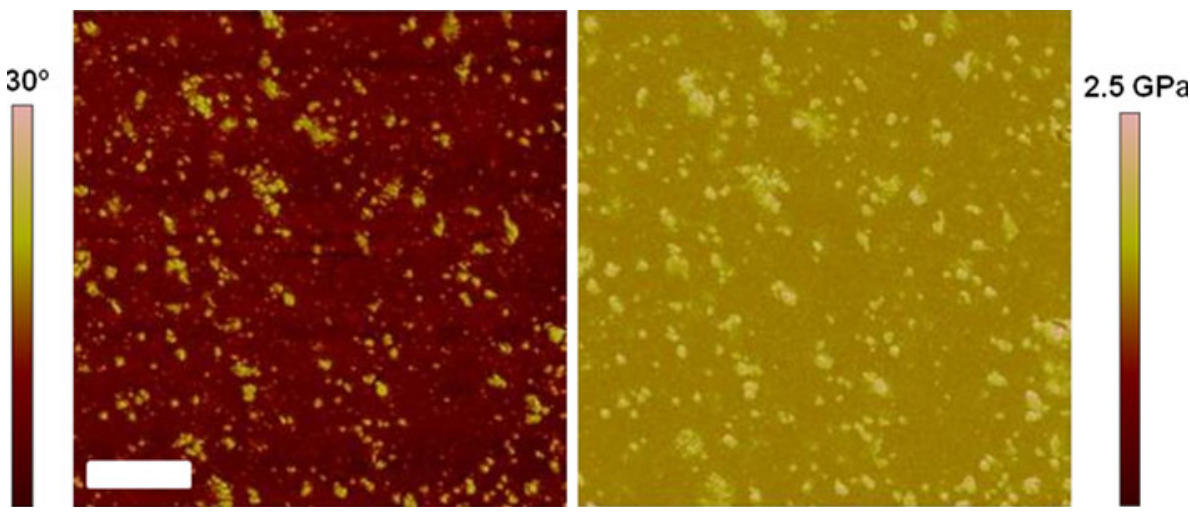

morphologies can be observed with particle diameters ranging from 20 to $80 \mathrm{~nm}$; the corresponding DMT modulus values range from 0.8 to $2 \mathrm{GPa}$. The surrounding matrix reveals moduli between 200 and $300 \mathrm{MPa}$. Comparing the images of SBR-5 phr silica, SBR-10 phr silica (Fig. 1a), and SBR-20 phr silica (Fig. 1b), an increase in the number of particles per area with higher modulus can be observed. Since the increase in the number of stiffer particles corresponds to the increase in the concentration of silica in the compound preparation, and the sizes observed are similar to those of primary silica particles, the particles are identified as the silica filler. In SBR, the Ultrasil 7005 silica was predominantly present as well dispersed primary particles and smaller aggregates.

By providing additional mechanical property contrast, HarmoniX AFM imaging nicely complements AFM phase imaging results (Fig. 2). While conventional phase contrast can help identify filler particles separately from the rubber matrix, HarmoniX imaging allows to quantitatively map the stiffness variation between the filler and the rubber

The SBR without any silica revealed sparse topographic and stiffness imprints which could be due to impurities or other components $(\mathrm{ZnO})$ used in the recipe. In unfilled SBR, the soft rubber part showed lower modulus values (70-100 MPa) which increased with incorporation of the filler particles (150-300 MPa) (data not shown).

\section{EPDM-silica}

The height, phase, and modulus images of 50 phr EPDMsilica are shown in Fig. 3. Silica particles are clustered in various regions of the surface of the imaged sections, 

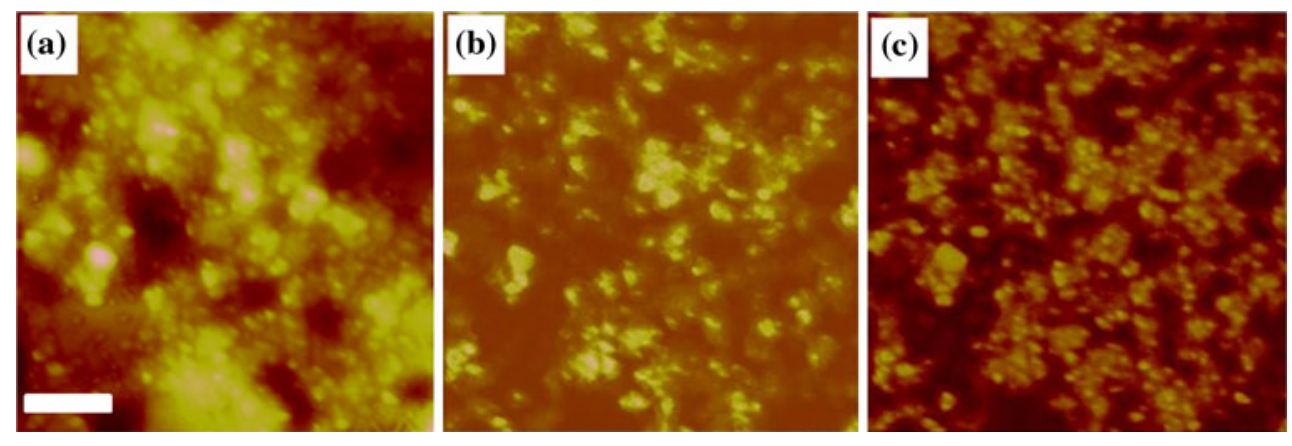

Fig. 3 HarmoniX AFM Images of EPDM filled with $50 \mathrm{phr}$ Ultrasil 7005: a: height, b: DMT modulus; c: phase signal; scan sizes: $5 \times 5 \mu$ m; scale bar: $1 \mu \mathrm{m}$; $z$-scales: height (a): $150 \mathrm{~nm}$; DMT modulus (b): $2 \mathrm{GPa}$; phase (c): $150^{\circ}$

leaving out domains without any silica. These domains show comparatively low modulus values around $70-100$ MPa. Compared to the silica-reinforced SBR, a significantly greater aggregation of the particles can be observed.

The brighter regions in the phase image correspond to the stiffer regions in the modulus images. The moduli of these regions are again in a similar range of $0.3-1 \mathrm{GPa}$. The soft part (indicated by brown/darker regions) has a modulus around 100-150 MPa. Hence these soft domains have lower moduli as compared to the SBR matrix showing values of 200-300 MPa. This might be an indication of poorer mixing and distribution of silica particles in the EPDM rubber matrix. Here particle aggregation was observed. We assume this leads to soft domains in the EPDM rubber matrix which show significantly less particles compared to SBR where particles might be incorporated in the subsurface below the matrix.

HarmoniX AFM measurements revealed that the dispersion of silica in EPDM is less homogeneous as compared to SBR with silica forming larger aggregates. In SBR, individual silica aggregates could be separately identified at lower concentrations of the filler and in general, it showed a homogeneous dispersion throughout the matrix. In the modulus image three phases can be seen: (1) silica aggregates, (2) the rubbery matrix, and (3) a stiffer phase surrounding the filler. This is consistent with the phase image indicating a fingerprint of a reinforced rubber.

\section{Unreinforced SBR}

The modulus values of the silica-free SBR are around 70-100 MPa (data not shown) which is lower than the corresponding values (200-300 MPa) observed for the silica-reinforced SBR. The larger modulus observed for reinforced rubbers might be directly related to the incorporation of the filler being accompanied by the apparent stiffening of the soft domains resulting from silica particles which are incorporated beneath the surface.
Stiffness differences for macroscopic bulk versus HarmoniX AFM surface values

Increasing the concentration of silica particles leads to a formation of filler-filler network leading to a tighter meshwork resulting in larger averaged bulk modulus. In contrast, the HarmoniX tip probes local modulus values (surface averaging) i.e., modulus at a localized silica particle or at a particular point in the soft rubber sample. The increase of the surface DMT modulus obtained by AFM imaging is explained by the increase in areal fraction of the Si particles.

The surface modulus values of the soft rubber part as obtained by HarmoniX AFM are significantly higher than the bulk elastic modulus from tensile measurements. Potential reasons for this discrepancy are discussed in the following.

The tensile tests are static measurements which sum up the various effects of filler-filler networks, filler rubber interaction, the effects of crosslinking between the polymer chains and other factors. Essentially bulk testing probes the soft matrix in a very low frequency range. Surface mean moduli values do not coincide with bulk values obtained via tensile testing which is also attributed to fundamentally different averaging procedures and effects that lead to the respective modulus values (surface and volume averaging). HarmoniX AFM provides surface averaged values of modulus at high lateral resolution. While measuring, it is possible that the rubber matrix appearing to be soft has some silica particles embedded beneath it, which give an effect on the HMX probe. A similar effect of the rubber on the filler could also be present. $\mathrm{Bulk}_{\mathrm{SiO}_{2}}$ has a modulus between 10 and $100 \mathrm{GPa}$ whereas we observe values around 2-3 GPa. This apparent softening could be an effect of the surrounding rubber which acts as a softening cushion.

HarmoniX AFM uses a "one point calibration" procedure for calibrating the HMX probe. One may argue that the values observed are higher because of using a stiffer 
polymer (microphase separated LDPE (ca. $100 \mathrm{MPa}$ ) in PS (ca. 1.6 GPa) for calibration. However, values as low as $40 \mathrm{MPa}$ have been measured by this technique with the same calibration procedure for polyurethane samples, which were also confirmed by Peak Force Tapping, another dynamic AFM imaging mode to derive the mechanical performance of polymeric materials [25].

Potential effects of the AFM tip geometry, its penetration depth and hence the contact area on the measurement of the sample moduli are taken into account in the calibration procedures. For the calibration sample and the rubber samples the same setpoints are chosen resulting in penetration depths of $2-10 \mathrm{~nm}$ of the probing AFM tip. HarmoniX Imaging AFM tips have nominal radii of ca. $10 \mathrm{~nm}$. Thus, we believe errors caused by local topography are small for the measured reinforced rubber and rubber blend samples. We note that around individual silica particles and aggregates, convoluting and smearing effects due to finite sized contact area between tip and sample should be considered. Assuming the above mentioned penetration depths of 2-10 $\mathrm{nm}$ of the probing tip very small contact areas result which in the regime of a few to tens of $\mathrm{nm}^{2}$. Hence we assume that related potential errors are negligible with silica particle diameters being in the range of $20-80 \mathrm{~nm}$ in diameter.

Regarding the underestimation of the silica particle modulus it is important to mention it has been reported that stiff inorganic materials show in general significantly lower modulus values than expected from their bulk values, most probably due to the accessible range of the HarmoniX probe being more accurate for softer materials with lower corresponding bulk modulus values ( $<2 \mathrm{GPa}$ ). In fact, for accurate modulus determination of very stiff materials a significantly stiffer probe would be fundamental; however, such probes are not available for HarmoniX Imaging. Importantly, the accurate determination of rubber modulus would not be possible with such a stiff probe.

The AFM measurements were done at very high frequencies (1 MHz torsional frequency) at which because of their viscoelastic, time-dependent nature, rubbers are much stiffer than normal range of frequencies. Also confinement effects due to the glassy rubber phase which leads to restricted mobility of polymer chains joined to the surface of filler might have an impact on the apparent higher modulus values.

A possible way for further investigations of the reasons of the difference between bulk properties and the AFM results would be performing dynamic tests on the samples using a Dynamic Mechanical Thermal Analyzer (DMTA). Although the frequency range of a common DMTA machine is up to $200 \mathrm{~Hz}$, by performing tests at low temperatures, it would be possible to calculate the modulus values at high frequencies, using the Williams-Landel-Ferry (WLF) equation [26]. However, this time-temperature superposition has also limitations in this case because it normally works well up to frequencies of even $100 \mathrm{kHz}$, while predicting modulus in frequencies in the range of $1 \mathrm{MHz}$, considering the frequency ranges and sensitivities of normal DMA instruments would be rather difficult. This would be anyway one of the scopes of the authors' further research.

\section{Improved dispersion behavior with Ultrasil ${ }^{\circledR} 7005$}

Two types of silica were used to study potential differences in dispersion behavior of the silica in the rubber matrix. Figure 4 shows height and modulus images for SBR reinforced with 10 phr Ultrasil VN3 and Ultrasil 7005.

Ultrasil VN3 forms large aggregates in SBR of sizes as large as $100-150 \mathrm{~nm}$. On the other hand, Ultrasil 7005 disperses much better in SBR forming significantly smaller particles of average sizes around 50-70 nm. Ultrasil 7005 belongs to the class of highly dispersible silicas, having a less compact structure as compared to silica VN3, and hence it is easy to break the agglomerates to smaller aggregates and primary particles and distribute them throughout the matrix.

\section{SBR/EPDM blends}

$20 \mathrm{phr}$ silica-reinforced SBR/EPDM blend samples were prepared in two different ratios of SBR/EPDM and studied by AFM (Fig. 5). Silica particles or agglomerates are not observed as separate particle morphologies in contrast to the silica-reinforced rubbers. Instead an overall separation in two phase domains can be seen. Soft and stiff domains of the rubber blend surface show largely different moduli (Fig. 5).

In Fig. 5a, corresponding to the larger EPDM content (70\%), the formation of large phases can be observed leaving out more or less continuous domains without any silica. These darker domains, which do not reveal dispersed silica particles, show modulus values as low as $30 \mathrm{MPa}$. Strikingly, in the 50/50 blend, dark domains with very low modulus values can be seen, which are interspersed between a continuous network of stiffer regions with modulus values as high as $2 \mathrm{GPa}$. We assume that the stiffness contrast arises from the silica particles preferring to partition into the SBR phase. As reported in the literature silica is more compatible with SBR than EPDM.

For the blends a bimodal DMT modulus distribution can be found which has maxima at $40 \mathrm{MPa}$ and ca. $0.5 \mathrm{GPa}$ (Fig. 5c) corresponding to a soft EPDM phase and the hard silica-reinforced SBR phase, respectively.

By utilizing the so called bearing analysis it is possible to analyze the distribution of surface elastic moduli over a rubber blend sample. Since the two phases differ largely in 
Fig. 4 HarmoniX AFM images of SBR reinforced with $10 \mathrm{phr}$ Ultrasil VN3 (a: height, c: DMT modulus) and 10 phr Ultrasil 7005 (b: height, d: DMT modulus); scan sizes: $5 \times 5 \mu \mathrm{m}$. Scale bar: $1 \mu \mathrm{m}$. z-Scales: height: $250 \mathrm{~nm}$, DMT modulus: $5 \mathrm{GPa}$

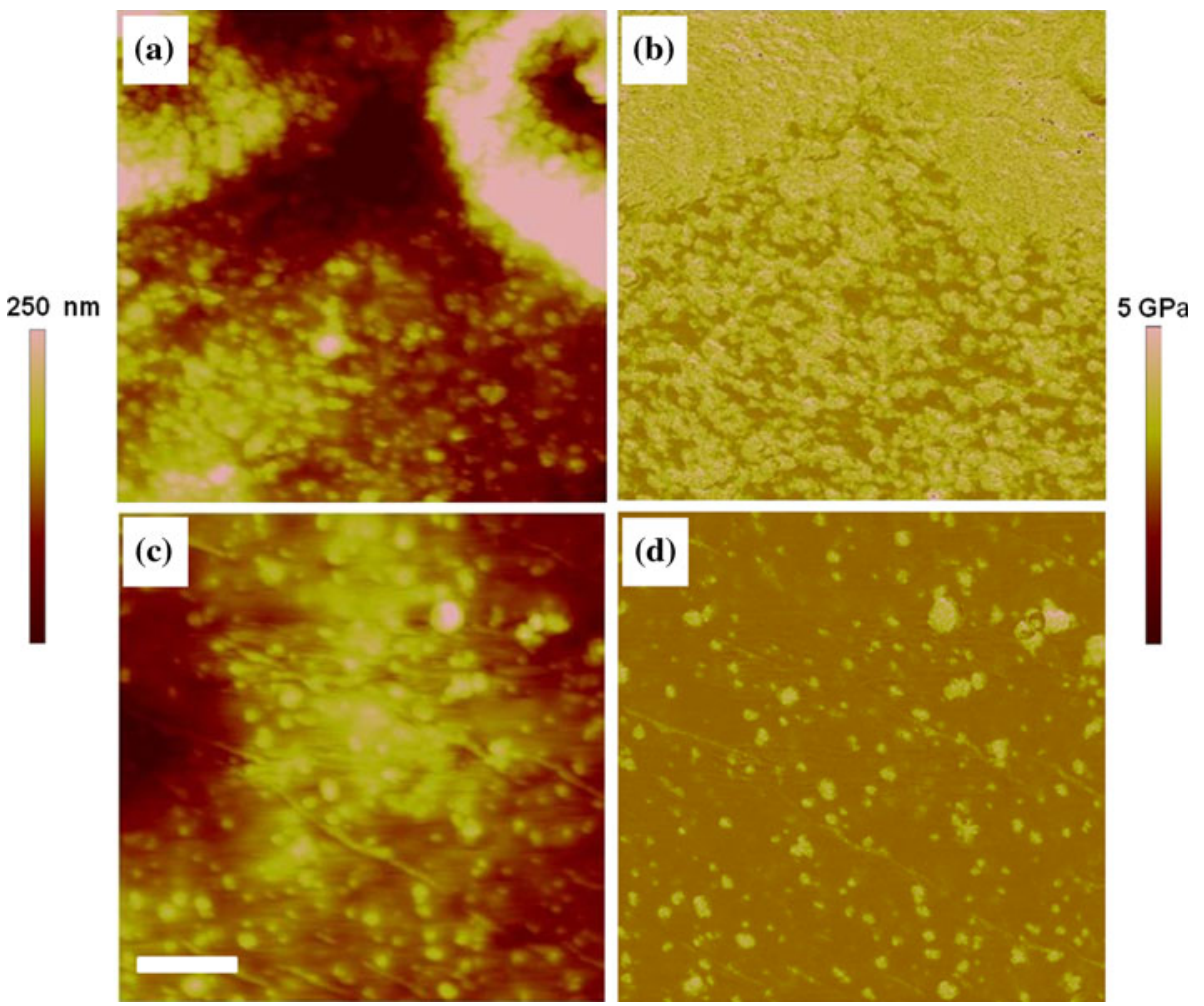

Fig. 5 DMT modulus images obtained from Harmonix AFM of SBR/EPDM blends filled with 20 phr Ultrasil VN3; a: 30/70 SBR/EPDM; b: 50/50 SBR/EPDM; c: modulus distribution of 50/50 SBR/ EPDM. Scale bar: $1 \mu \mathrm{m}$
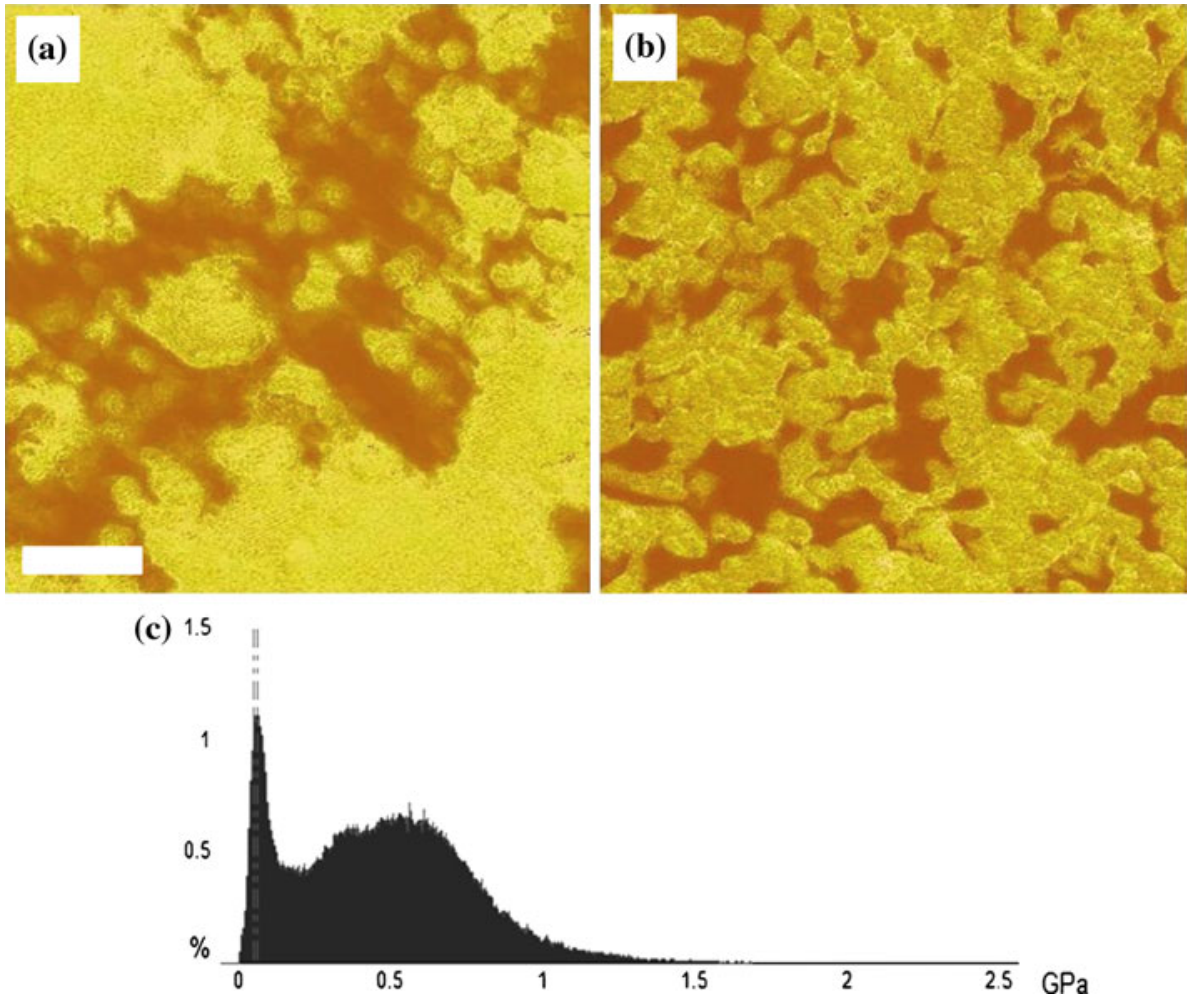

their stiffness, an upper and lower threshold of modulus values was defined to solely distinguish between a hard and a soft modulus value. In this manner the respective hard and soft domain area fractions were determined and compared to the compositional ratio used for the rubber preparation (Fig. 6).

The above analysis shows that the stiffer regions constitute 36 and $48 \%$ in the 30/70 SBR/EPDM and 50/50 
Fig. 6 Bearing analysis: left: 30/70 SBR/EPDM; right: 50/50 SBR/EPDM
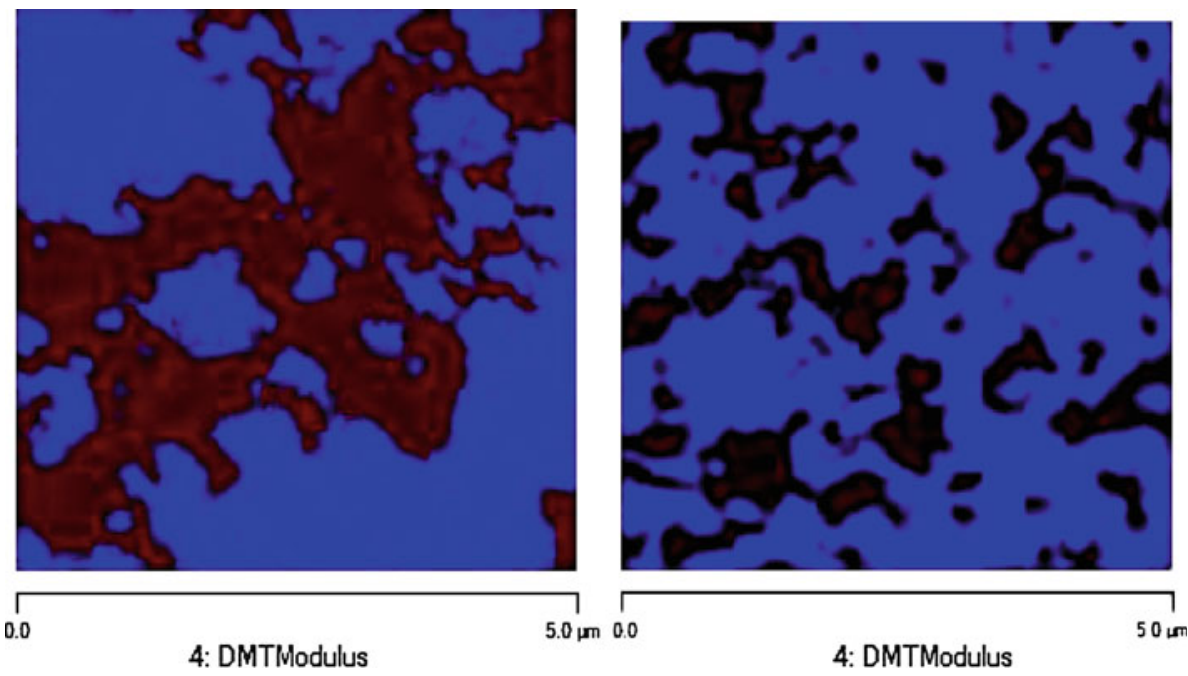

Bearing Area: $9.16 \mu \mathrm{m}^{2}$

Bearing Area percent: $36.6 \%$
Bearing Area: $11.95 \mu \mathrm{m}^{2}$

Bearing Area percent: $47.8 \%$
SBR/EPDM blends, respectively. Since these percentages are close to the actual amounts of SBR in the blend according to the recipe compositions, we conclude that the SBR phase has become stiffer with respect to the EPDM due to the greater tendency of the silica to partition into the SBR phase. It can be concluded, that the ratio in which the sample was prepared, remains intact in the bulk and the silica prefers to move into the SBR phase, increasing its modulus to values as high as 1-2 GPa while the EPDM phase remains with very less amount of silica and its modulus remains around 20-60 MPa. The lower value of elastic modulus of the EPDM phase in the blend, compared to the blank EPDM compound can be attributed to the presence of Sunpar oil in the compound which has a very good affinity with EPDM and decreases the rubber modulus.

\section{Conclusion}

In this study, the surface morphologies as well as the elastic moduli of silica-reinforced rubbers and rubber blends were investigated by AFM imaging and AFM-based HarmoniX material mapping. Stiffness values were compared to the corresponding macroscopic tensile values.

The bulk modulus values showed an increase in accordance with increasing filler concentration. The respective DMT moduli maps obtained by HarmoniX AFM imaging revealed an increase of the areal fraction of silica particles with rising concentration in the compound preparation mixture. Significantly higher elastic moduli were observed by AFM then by bulk tensile testing. While the stiff silica particles show modulus values as high as $2 \mathrm{GPa}$, the rubber matrix reveals modulus values in the range of $30 \mathrm{MPa}$ (in case of rubber blends)-300 $\mathrm{MPa}$ (individual rubbers). As potential reasons for the observed differences between bulk modulus values and those measured, different averaging procedures like surface and bulk averaging of AFM versus tensile testing, different filler distributions in SBR and EPDM, and the AFM modulus calibration procedures have been discussed.

HarmoniX AFM measurements revealed the formation of larger silica aggregates in EPDM in contrast to SBR where isolated silica particles can be observed. At silicareinforced rubber blends a phase separation into a soft (ca. $40 \mathrm{MPa}$ ) and a significantly harder phase could be observed (ca. $500 \mathrm{MPa}-1.5 \mathrm{GPa}$ ) indicating the incooperation of silica particles exclusively in the SBR phase. In case of SBR/EPDM blends, a phase separation was observed and the two phases could be distinguished by the large differences in their stiffness. While the modulus values in the stiffer phase were observed to be as high as $2-3 \mathrm{GPa}$, in the soft part the values were as low as 30-40 MPa.

Acknowledgements P.S. and G.J.V. thank the MESA ${ }^{+}$Institute for Nanotechnology for funding. G.J.V. acknowledges support by Veeco in form of the Veeco HarmoniX research grant. M.S. and J.N. acknowledge support from the Dutch Polymer Institute (DPI) under project \#664.

Open Access This article is distributed under the terms of the Creative Commons Attribution Noncommercial License which permits any noncommercial use, distribution, and reproduction in any medium, provided the original author(s) and source are credited. 


\section{References}

1. Hoffman W (1989) Rubber technology handbook. Oxford University Press, Hanser Publishers, New York

2. Bhowmick AK (2008) Current topics in elastomers research. CRC Press, Boca Raton

3. Dierkes WK, Noordermeer JWM (2009) In: White J, De SK, Naskar K (eds) Rubber technologist's handbook, vol 2. SmithersRapra, Shawbury, p 97

4. Ikeda Y, Katoh A, Shimanuki J, Kohjiya S (2004) Macromol Rapid Comm 25(12):1186

5. Yerina N, Magonov S (2003) Rubber Chem Technol 76(4):846

6. Vancso GJ, Schön P, Duvigneau J (2009) Microsc Anal 23:5

7. Vancso GJ, Schönherr H (2010) Scanning force microscopy of polymers. Springer, Berlin, Heidelberg

8. Niedermeier W, Raab H, Maier P, Kreitmeier S, Göritz D (1995) Kautsch Gummi Kunstst 48(9):611

9. Niedermeier W, Raab H, Stierstorfer J, Kreitmeier S, Goritz D (1994) Kautsch Gummi Kunstst 47(11):799

10. van Bevervoorde-Meilof EWE, van Haeringen-Trifonova D, Vancso GJ, Van der Does L, Bantjes A, Noordermeer JWM (2000) Kautsch Gummi Kunstst 53(7-8):426

11. Trifonova-Van Haeringen D, Schönherr H, Vancso GJ, van der Does L, Noordermeer JWM, Janssen PJP (1999) Rubber Chem Technol 72(5):862

12. Garcia R, Perez R (2002) Surf Sci Rep 47(6-8):197
13. Garcia R, Tamayo J, San Paulo A (1999) Surf Interface Anal 27(5-6):312

14. Reynaud C, Sommer F, Quet C, El Bounia N, Duc TM (2000) Surf Interface Anal 30(1):185

15. Butt HJ, Cappella B, Kappl M (2005) Surf Sci Rep 59(1-6):1

16. Tranchida D, Piccarolo S, Soliman M (2006) Macromolecules 39(13):4547

17. Sahin O (2007) Rev Sci Instrum 78(10):103707

18. Sahin O, Erina N (2008) Nanotechnology 19:445717

19. Sahin O, Magonov S, Su C, Quate CF, Solgaard O (2007) Nat Nanotechnol 2(8):507

20. Reuvekamp LAEM, Debnath SC, Ten Brinke JW, Van Swaaij PJ, Noordermeer JWM (2004) Rubber Chem Technol 77(1):34

21. Reuvekamp LAEM, Ten Brinke JW, Van Swaaij PJ, Noordermeer JWM (2002) Rubber Chem Technol 75(2):187

22. Reuvekamp LAEM, Ten Brinke JW, van Swaaij PJ, Noordermeer JWM (2002) Kautsch Gummi Kunstst 55(1-2):41

23. Jesionowski T, Krysztafkiewicz A, Zurawska J, Bula K (2009) J Mater Sci 44(3):759. doi:10.1007/s10853-008-3170-4

24. Li H, Sun J, Song YH, Zheng Q (2009) J Mater Sci 44(7):1881. doi:10.1007/s10853-008-3223-8

25. Schön P, Bagdi K, Molnár K, Markus P, Pukánszky B, Vancso, GJ (2010) Eur Polym J (in press)

26. Williams ML, Landel RF, Ferry JD (1955) J Am Chem Soc $77: 3701$ 